\title{
Conversion risk factors in laparoscopic colorectal surgery
}

\author{
Marcela Rabasová', Lubomír Martínek² \\ 1Department of Mathematics and Descriptive Geometry, VŠB - Technical University of Ostrava, Czech Republic \\ ${ }^{2}$ Clinic of Surgery, University Hospital Ostrava, Czech Republic
}

Videosurgery Miniinv 2012; 7 (4): 240-245

DOI: $10.5114 /$ wiitm.2011.28906

\begin{abstract}
Introduction: This study is aimed at identifying important risk factors associated with conversion of laparoscopic colorectal surgery. Laparoscopic surgery is usually associated with less operative trauma, more favourable post-operative course and lower morbidity than open surgery. However, conversion is connected with some risks according to some authors.

Aim: To identify the risk factors associated with conversion and to create a model to predict possible conversion for a patient before surgery.

Material and methods: The source data file contained information about 649 patients who underwent laparoscopic colorectal surgery between 2001 and 2009 at the University Hospital Ostrava, Czech Republic. Conversion to open surgery was necessary in 54 cases. The variables gender, body mass index (BMI), American Society of Anesthesiologists (ASA) classification, stage of disease, number of previous operations and operation severity were included in the analysis as the potential risk factors of conversion. Discriminant analysis was used for the data evaluation; statistical software SPSS 17 and NCSS 2004 were used for the calculations.

Results: The created model had only low discriminating ability. The variable ASA classification was identified as the most important risk factor of conversion, followed by the variables operation severity, gender and BMI.

Conclusions: Discriminant analysis did not find the chosen input variables satisfactory enough to make a reasonable model for the prediction of conversion. The expected fact was confirmed that large bowel surgery and greater BMI mean greater risk of conversion, whereas there is no reason to refuse laparoscopy for a patient with higher ASA classification.
\end{abstract}

Key words: colorectal surgery, laparoscopy, conversion, risk factors, discriminant analysis.

\section{Introduction}

This study examines risk factors of conversion of laparoscopic colorectal surgery. Laparoscopic surgery is usually associated with less operative trauma, more favourable post-operative course and lower morbidity than open techniques. Many research studies have compared morbidity and mortality after both types of surgery. One of them was carried out at the Clinic of Surgery, University Hospital Ostrava in 2006. Logistic regression and discriminant analysis were applied to the data from colorectal operations and a significantly lower morbidity among patients operated on laparoscopically was demonstrated [1].

However, there are also some negative factors in using laparoscopic techniques in colorectal surgery, which can contribute to morbidity to a large extent, e.g. the risk of capnoperitoneum, longer operative time 
and extreme positioning of patients, and also the risk of conversion. The results from converted laparoscopic operations are demonstrably worse than the results from open operations according to some research papers [2-4]; thus the open technique should be considered if the risk of conversion is too high.

\section{Aim}

The current study aimed to identify the important risk factors associated with the conversion of laparoscopic to open colorectal surgery and to create a model to predict possible conversion for a patient before surgery.

\section{Material and methods}

The processed data file consists of information about 649 patients (411 men and 238 women) who underwent elective laparoscopic colorectal surgery between 2001 and 2009 at the University Hospital Ostrava, Czech Republic. The average age was 63.72 \pm 12.84 years old (range: $18-97$ years old). Conversion to open surgery was necessary in 54 cases (8.3\%). The basic data of each patient were monitored, such as the data describing the surgery, post-operative process and complications and the physiological state of the patient before surgery (body mass index (BMI), American Society of Anesthesiologists (ASA) classification, age, cardiac stress, blood pressure, etc.). Many descriptive studies (for example [5-7]) have identified various risk factors of conversion to open surgery. According to these studies and to the experience of the surgeons from the Clinic of Surgery, University Hospital Ostrava, the following six independent variables were included in the analysis: gender, BMI, ASA classification, stage of disease, number of previous operations and operation severity. These quantities play the role of independent variables. The dependent variable here is the surgical technique. Two states of this variable are distinguished for the analysis: laparoscopy with conversion and laparoscopy without conversion.

Numeric values were assigned to nominal variables in this way: gender ( 1 - female, 0 - male), stage of disease (values 1-4 were assigned in accordance with histological tumour node metastasis (TNM) classification for colorectal cancer; a value of 0 represents benign disease), operation severity (values 2, 4, 8 were assigned in accordance with methods published by Copeland et al. [8]), surgical technique (1-laparoscopy with conversion, 0 - laparoscopy without conversion).

Discriminant analysis was used to find the variable with the greatest impact on possible conversion and to create the model for prediction of conversion for a patient before surgery.

Discriminant analysis is a statistical method used for multivariate data processing. Its principles have been presented by Huberty and Olejnik [9] and Neil [10]. Discriminant analysis serves as a descriptive tool for describing differences among groups of units with regard to the group of independent variables and for the classification of objects with unknown group membership into predefined groups.

Statistical software SPSS version 17 (PASW Statistics 17.0) and NCSS 2004 were used for calculations.

\section{Results}

The source data file consists of information about 649 patients who underwent laparoscopic colorectal surgery. It was divided into two groups: patients who required conversion (54 cases) and patients without conversion (595 cases). The impact of the following six variables on conversion was examined: gender, BMI, ASA classification, stage of disease, number of previous operations and operation severity.

Basic descriptive statistics were first computed to obtain an initial idea about the whole sample. They are presented in Table I. We used the Mann-Whitney test for testing differences between groups for the continuous parameter $\mathrm{BMI}$, the $\chi^{2}$ test for the dichotomous parameter gender, and the KruskalWallis test for the remaining parameters, which are ordinal. No significant differences were found between the groups with and without conversion, except for the variables ASA classification $(p=0.011)$ and operation severity $(p=0.008)$.

Multivariate analysis of variance was then performed (see Table II) to find out if the variables differ significantly in individual groups in the multivariate context. The hypothesis of equality of group mean vectors was rejected at the significance level $1 \%$ ( $p=0.006)$; thus the influence of these six monitored quantities upon conversion was confirmed. The additional one-way tests for individual variables confirmed that the variables ASA classification $(p=0.011)$ and operation severity $(p=0.022)$ have the greatest impact on conversion. Finally, we used discriminant analysis to confirm the significance of these variables and to create a model to predict possible conversion for a patient before surgery. 
The canonical discriminant function coefficients were calculated (Table III), which can be used for predicting the conversion. They indicate (analogously to the regression analysis coefficients) the individual impact of the original variables on the canonical vari- able, provided that the other variables are constant. On the basis of these coefficients the discriminant score of the $i$-th patient could be computed as:

$y_{i}=1.138 x_{i, 1}-0.064 x_{i, 2}+0.884 x_{i, 3}+0.017 x_{i, 4}-$ $0.462 x_{i, 5}-0.287 x_{i, 6}+0.722$, where: $x_{i, 1}=$ value of the

Table I. Descriptive statistics

\begin{tabular}{|c|c|c|c|c|}
\hline Parameter & With conversion & Without conversion & Total & Value of $p$ \\
\hline \multicolumn{5}{|l|}{ Gender } \\
\hline Men, $n(\%)$ & $40(74.1)$ & $371(62.4)$ & $411(63.3)$ & 0.087 \\
\hline Women, $n(\%)$ & $14(25.9)$ & $224(37.6)$ & $238(36.7)$ & \\
\hline \multicolumn{5}{|l|}{ Body mass index [years] } \\
\hline Median (5th; $95^{\text {th }}$ percentile) & $27.2(20.0 ; 33.8)$ & $26.1(19.8 ; 33.7)$ & $26.2(19.9 ; 33.8)$ & 0.205 \\
\hline Range & $14.6-38.2$ & $15.6-45.7$ & $14.6-45.7$ & \\
\hline Average \pm SD & $27.1 \pm 4.9$ & $26.5 \pm 4.4$ & $26.6 \pm 4.5$ & \\
\hline \multicolumn{5}{|l|}{ ASA classification, $n(\%)$} \\
\hline 1 & $10(18.5)$ & 77 (12.9) & $87(13.4)$ & 0.011 \\
\hline 2 & $31(57.4)$ & $274(46.1)$ & $305(47.0)$ & \\
\hline 3 & $13(24.1)$ & $216(36.3)$ & $229(35.3)$ & \\
\hline 4 & $0(0.0)$ & $28(4.7)$ & $28(4.3)$ & \\
\hline \multicolumn{5}{|l|}{ Stage of disease, $n(\%)$} \\
\hline 0 & $14(25.9)$ & $101(17.0)$ & $115(17.7)$ & 0.570 \\
\hline 1 & $5(9.3)$ & $86(14.5)$ & $91(14.0)$ & \\
\hline 2 & $8(14.8)$ & $125(21.0)$ & $133(20.5)$ & \\
\hline 3 & $20(37.0)$ & $185(31.1)$ & $205(31.6)$ & \\
\hline 4 & $7(13.0)$ & $98(16.5)$ & $105(16.2)$ & \\
\hline \multicolumn{5}{|l|}{ Number of operations, $n(\%)$} \\
\hline 0 & $26(48.1)$ & $331(55.6)$ & $357(55.0)$ & 0.355 \\
\hline 1 & $21(38.9)$ & $188(31.6)$ & $209(32.2)$ & \\
\hline 2 & $5(9.3)$ & $63(10.6)$ & 68 (10.5) & \\
\hline 3 & $2(3.7)$ & $11(1.8)$ & $13(2.0)$ & \\
\hline 4 & $0(0.0)$ & $2(0.3)$ & $2(0.3)$ & \\
\hline \multicolumn{5}{|l|}{ Operation severity, $n$ (\%) } \\
\hline 2 & $1(1.9)$ & $87(14.6)$ & $88(13.6)$ & 0.008 \\
\hline 4 & $41(75.9)$ & $420(70.6)$ & $461(71.0)$ & \\
\hline 8 & $12(22.2)$ & $88(14.8)$ & $100(15.4)$ & \\
\hline
\end{tabular}


variable gender, $x_{i, 2}=$ value of the variable $\mathrm{BMI}, x_{i, 3}=$ value of the variable ASA classification, $x_{i, 4}=$ value of the variable stage of disease, $x_{i, 5}=$ value of the variable number of previous operations, $x_{i, 6}=$ value of the variable operation severity of the $i$-th patient.

Each patient is then classified into that group (with or without conversion) where the group centroid is closer to his discriminant score. The groups' centroids are presented in Table IV. For example, if a patient who is a woman with BMI of $18 \mathrm{~kg} / \mathrm{m}^{2}$, ASA grade 2 , benign disease and one previous operation is undergoing surgery of severity 2 , her discriminant score is: $y=1.138 \times$ $1-0.064 \times 18+0.884 \times 2+0.017 \times 0-0.462 \times 1-$ $0.287 \times 2+0.722=1.44$. Such a patient would be classified into group 0 (without conversion), because their discriminant score is closer to the group centroid of group 0, which is 0.051 .

The accuracy of this classification rule is recorded in a verification matrix (Table $\mathrm{V}$ ). The discriminant score of each patient was computed and each patient was classified into one of the two groups with conversion or without conversion. The predicted group membership was then compared with the actual one. The numbers and percentages of the correctly and wrongly classified patients are shown in the upper half of the table ("Original"). The total number of correctly classified patients is 407 (369 without and 38 with conversion), which is $62.7 \%$. This number determines the probability of correct classification. However, this value is overestimated, so the cross-validated method was used to obtain an unbiased estimation of the probability, which is only $61.6 \%$. Regrettably, this number is so small that such a model cannot be used in practice.

We can find out which quantitative variable has the greatest impact on conversion from the correlation coefficients of the predictor variables with the canonical discriminant function. They are computed in Table VI. The coefficients with larger absolute values correspond to the variables with greater discriminating ability, which implies that the most important variable for discrimination is ASA classification with the coefficient 0.592. A larger value of this variable means a smaller risk of conversion. The second important variable is operation severity; larger values mean greater risk of conversion.

\section{Discussion}

The end of the $20^{\text {th }}$ century was characterized by rapid progress in minimally invasive techniques in
Table II. Multivariate analysis of variance

\begin{tabular}{|lccc|}
\hline $\begin{array}{l}\text { MANOVA Tests Section } \\
\text { Term (DF) } \\
\text { Test statistic } \\
\text { A(1): surgical_technique }\end{array}$ & $\begin{array}{c}\text { Test } \\
\text { value }\end{array}$ & $\begin{array}{c}\text { Value } \\
\text { of } p\end{array}$ & (0.05) \\
\hline Wilks' lambda & 0.9720 & 0.006 & Reject \\
\hline Gender & 0.6802 & 0.087 & Accept \\
\hline Body mass index & 17.3496 & 0.352 & Accept \\
\hline ASA classification & 3.6675 & 0.011 & Reject \\
\hline Stage of disease & 0.9399 & 0.470 & Accept \\
\hline Number of operations & 0.3882 & 0.424 & Accept \\
\hline Operation severity & 15.1228 & 0.022 & Reject \\
\hline
\end{tabular}

Table III. Canonical discriminant function coefficients

\begin{tabular}{|lc|}
\hline Parameter & Function 1 \\
\hline Gender & 1.138 \\
\hline Body mass index & -0.064 \\
\hline ASA classification & 0.884 \\
\hline Stage of disease & 0.017 \\
\hline Number of operations & -0.462 \\
\hline Operation severity & -0.287 \\
\hline (Constant) & 0.722 \\
\hline
\end{tabular}

Table IV. Group centroids

\begin{tabular}{|lc|}
\hline Surgical technique & Group centroid \\
\hline Without conversion & 0.051 \\
\hline With conversion & -0.562 \\
\hline
\end{tabular}

colorectal surgery. The proportion of laparoscopic colorectal operations is still increasing worldwide [11, 12], including among complicated surgical procedures [13]. As the demand for laparoscopic colorectal surgery increases, interest in the risk of conversion to open surgery grows as well.

Although some authors did not find converted laparoscopic operations significantly worse than standard, open techniques [14-16], some others did. Various aspects are taken into account when comparing the results of converted laparoscopic tech- 
Table V. Classification results

\begin{tabular}{|c|c|c|c|c|c|}
\hline \multicolumn{3}{|c|}{ Surgical technique } & \multicolumn{2}{|c|}{ Predicted group membership } & \multirow[t]{2}{*}{ Total } \\
\hline & & & Without conversion & With conversion & \\
\hline \multirow[t]{4}{*}{ Original } & Count & Without conversion & 369 & 226 & 595 \\
\hline & & With conversion & 16 & 38 & 54 \\
\hline & $\%$ & Without conversion & 62.0 & 38.0 & 100.0 \\
\hline & & With conversion & 29.6 & 70.4 & 100.0 \\
\hline \multirow[t]{4}{*}{ Cross-validated } & Count & Without conversion & 369 & 226 & 595 \\
\hline & & With conversion & 23 & 31 & 54 \\
\hline & $\%$ & Without conversion & 62.0 & 38.0 & 100.0 \\
\hline & & With conversion & 42.6 & 57.4 & 100.0 \\
\hline
\end{tabular}

$62.7 \%$ of original grouped cases correctly classified, $61.6 \%$ of cross-validated grouped cases correctly classified

Table VI. Structure matrix

\begin{tabular}{|lc|}
\hline Variables & Correlation coefficients \\
\hline ASA classification & 0.592 \\
\hline Operation severity & -0.531 \\
\hline Gender & 0.397 \\
\hline Body mass index & -0.216 \\
\hline Number of operations & -0.185 \\
\hline Stage of disease & 0.168 \\
\hline
\end{tabular}

niques and open ones. Some papers reported longer surgery time [15, 17], longer post-operative hospital stay [18, 19], more frequent post-operative complications [18], higher costs [19] and higher morbidity and shorter survival time $[18,20-23]$ in patients who underwent conversion. But there is still not a clear conclusion in comparing these two techniques in the contemporary literature.

Laparoscopic conversion rates in colorectal surgery, which vary from $7-25 \%$ in larger studies to $2-41 \%$ in smaller series [17, 22], depend on many factors. Previous studies have identified various risk factors associated with conversion to open surgery such as age, gender, BMI, ASA classification, number of previous operations, diagnosis, etc. Some studies reported a significantly larger proportion of men in "converted" groups [18, 24, 25], especially in the case of rectal diseases [19]. Age was found as a risk factor of conversion by Janson et al. [19] and in the case of rectal diseases also by Tan et al. [25]. Some other studies did not find age as a risk factor at all [24, 26].
Also concerning ASA classification the conclusions are not unequivocal $[19,25,26]$. The multicentre, randomized study MRC CLASSIC [21] concluded that the risk of conversion grows in patients with ASA $>3$ in these cases: right-sided and left-sided hemicolectomy, sigmoid resection, low anterior resection and abdominoperineal amputation. Another factor associated with a higher conversion rate in colorectal surgery is $\mathrm{BMI}>27.5 \mathrm{~kg} / \mathrm{m}^{2}$ [24], > $29 \mathrm{~kg} / \mathrm{m}^{2}$ [27], $>30 \mathrm{~kg} / \mathrm{m}^{2}$ [7]. For example, Pilarsky et al. [7] reported a significantly higher conversion (and also complication) rate for obese patients with a BMI exceeding $30 \mathrm{~kg} / \mathrm{m}^{2}$ in his group of 162 patients (19\% of them were obese). The conversion rate was $39 \%$ for the patients with $\mathrm{BMI}>30 \mathrm{~kg} / \mathrm{m}^{2}$ and $13.5 \%$ for the others. Various studies have shown that the number of previous operations also has a significant influence on possible conversion to open surgery [28-30]. Reported conversion rates were $16.5-26.1 \%$ in the groups with and $5.1-15 \%$ in the groups without previous intra-abdominal operations.

The present study focused on the risk of conversion of laparoscopic to open colorectal surgery with regard to the following six factors: gender, BMI, ASA classification, stage of disease, number of previous operations and operation severity. Discriminant analysis did not find the chosen input variables satisfactory enough to make a sufficient model for the prediction of conversion, which means that a new choice of independent predictors is necessary. This task will be solved in the future using a larger group of patients.

In our study, we found significant association of conversion with ASA classification and operation 
severity. Paradoxically, larger values of the variable ASA classification correspond to a smaller risk of conversion, which means that the patients with a higher ASA score were not associated with higher risk of conversion in our data set. Regarding the variable operation severity, larger values mean greater risk of conversion, which confirms the fact that large bowel operations exceed the technical limitations of laparoscopic surgery. No significant individual impact of the variables gender, BMI, stage of disease and number of previous operations on conversion was found.

\section{Acknowledgments}

This article has been elaborated in the framework of the IT4Innovations Centre of Excellence project, reg. no. CZ.1.05/1.1.00/02.0070 supported by Operational Programme 'Research and Development for Innovations' funded by Structural Funds of the European Union and state budget of the Czech Republic.

\section{References}

1. Martínek L, Dostalík J, Vávra P, et al. Implementation of POSSUM Scoring System in assessing morbidity after laparoscopic colorectal surgery. Rozhl Chir 2008; 87: 26-31.

2. Chan ACY, Poon JTC, Fan JKM, et al. Impact of conversion on the long-term outcome in laparoscopic resection of colorectal cancer. Surg Endosc 2008; 22: 2625-30.

3. Marusch F, Gastinger I, Schneider C, et al. Importance of conversion for results obtained with laparoscopic colorectal surgery. Dis Colon Rectum 2001; 44: 207-14.

4. The Colon Cancer Laparoscopic or Open Resection Study Group. Buunen M, Veldkamp R, Hop WC, et al. Laparoscopic surgery versus open surgery for colon cancer: short-term outcomes of a randomized trail. Lancet Oncol 2009; 10: 44-52.

5. Yong L, Deane M, Monson JR, Darzi A. Systematic rewiev of laparoscopic surgery for colorectal malignancy. Surg Endosc 2001; 15: 1431-9.

6. Tekkis PP, Senagore AJ, Delaney CP. Conversion rates in laparoscopic colorectal surgery. Surg Endosc 2005; 19: 47-54.

7. Pilarsky AJ, Saida Y, Yamaguchi T, et al. Is obesity a high-risk factor for laparoscopic colorectal surgery? Surg Endosc 2002; 16: 855-8.

8. Copeland GP, Jones D, Wakters M. POSSUM: a scoring system for surgical audit. Br I Surg 1991; 78: 356-60.

9. Huberty CJ, Olejnik S. Applied MANOVA and discriminant analysis. Wiley-Interscience. New York, USA 2006

10. Neil HT. Applied multivariate analysis. Springer-Verlag, New York 2002.

11. Piatkowski J, Jackowski M. Laparoscopic colon resections - own experience report. Videosurgery Miniinv 2009; 4: 135-7.

12. Duda M, Gryga A, Czudek S, Skalický P. Twenty years of minimally invasive surgery in the Czech Republic. Videosurgery Miniinv 2011; 6: 42-7.
13. Skrovina M, Soumarova R, Kycina R, et al. Anastomotic leakage after laparoscopic total mesorectal excision for low rectal cancer. Videosurgery Miniinv 2011; 6: 5-11.

14. Laurent C, Leblanc F, Wütrich P, et al. Laparoscopic versus open surgery for rectal cancer. Long term oncological results. Ann Surg 2009; 250: 54-61.

15. Franko J, Fassler SA, Rezvani M, et al. Conversion of laparoscopic colon resection does not affect survival in colon cancer. Surg Endosc 2008; 22: 2631-4.

16. Casillas S, Delaney CP, Senagore AJ, et al. Does conversion of a laparoscopic colectomy adversely affect patient outcome? Dis Colon Rectum 2004; 47: 1680-5.

17. Gervaz P, Pikarsky A, Utech M, et al. Converted laparoscopic colerectal surgery. Surg Endosc 2001; 15: 827-32.

18. Chan ACY, Poon JTC, Fan JKM, et al. Impact of conversion on the long-term outcome in laparoscopic resection of colerectal cancer. Surg Endosc 2008; 22: 2625-30.

19. Janson M, Bjorholt I, Carlsson P, et al. Randomized clinical trial of the cost of open and laparoscopic surgery for colonic cancer. Br J Surg 2004; 91: 409-17.

20. Nelson H. A comparison of laparoscopically assisted and open colectomy for colon cancer. The clinical outcomes of surgical therapy study group. N Engl J Med 2004; 350: 2050-9.

21. Guillou PJ, Quirke P, Thorpe H, et al. MRC CLASSIC trial group: Short-term endpoints of conventional versus laparoscopicassisted surgery in patients with colorectal cancer: multicentre, randomised controlled trial. Lancet 2005; 365: 1718-26.

22. Marusch F, Gastinger I, Schneider C, et al. Importance of conversion for results obtained with laparoscopic colorectal surgery. Dis Colon Rectum 2001; 44: 207-14.

23. The Colon Cancer Laparoscopic or Open Resection Study Group. Buunen M, Veldkamp R, Hop WC, et al. Laparoscopic surgery versus open surgery for colon cancer: short-term outcomes of a randomized trial. Lancet Oncol 2009; 10: 44-52.

24. Schwandner O, Schiedeck TH, Bruch HP. The role of conversion in laparoscopic colorectal surgery. Do predictive factors exist? Surg Endosc 1999; 13: 151-6.

25. Tan PY, Stephens JH, Rieger NA, Hewett PJ. Laparoscopically assisted colectomy: a study of risk factors and predictors of open conversion. Surg Endosc 2008; 22: 1708-14.

26. Thorpe H, Jayne DG, Guillou PJ, et al. Patient factors influencing conversion from laparoscopically assisted to open surgery for colorectal cancer. Br J Surg 2008; 95: 199-205.

27. Pandya S, Murria JJ, Coller JA, et al. Laparoscopic colectomy: indications for conversion to laparotomy. Arch Surg 1999; 134: 471-5.

28. Franko J, O'Connel BG, Mehall JR, et al. The influence of prior abdominal operations on conversion and complication rates in laparoscopic colorectal surgery. JSLS 2006; 10: 169-75.

29. Vignali A, Di Palo S, De Nardi P, et al. Impact of previous abdominal surgery on the outcome of laparoscopic colectomy: a casematched control study. Tech Coloproctol 2007; 11: 241-6.

30. Gonzales Al, Malagon MA, et al. Impact of previous abdominal surgery on colorectal laparoscopy results: a comparative clinical study. Surg Laparosc Endosc Percutan Tech 2006; 16: 8-11.

Received: 21.08.2011, Revised: 1.10.2011, Accepted: 23.04.2012. 